Trinity University

Digital Commons @ Trinity

Chemistry Faculty Research

Chemistry Department

3-13-2006

\title{
Tuning Supported Catalyst Reactivity with Dendrimer-Templated Pt-Cu Nanoparticles
}

Natalie N. Hoover

Trinity University

Bethany J. Auten

Trinity University

Bert D. Chandler

TrinityUniversity, bchandle@trinity.edu

Follow this and additional works at: https://digitalcommons.trinity.edu/chem_faculty

Part of the Chemistry Commons

\section{Repository Citation}

Hoover, N.N., Auten, B.J., Chandler, B.D. Tuning supported catalyst reactivity with dendrimer-templated Pt-Cu nanoparticles. (2006) Journal of Physical Chemistry B, 110(17), pp. 8606-8612.

This Article is brought to you for free and open access by the Chemistry Department at Digital Commons @ Trinity. It has been accepted for inclusion in Chemistry Faculty Research by an authorized administrator of Digital Commons @ Trinity. For more information, please contact 


\title{
Tuning Supported Catalyst Reactivity with Dendrimer-Templated Pt-Cu Nanoparticles
}

\author{
Natalie N. Hoover, Bethany J. Auten, and Bert D. Chandler* \\ Department of Chemistry, Trinity University, One Trinity Place, San Antonio, Texas 78212-7200 \\ Received: February 8, 2006; In Final Form: March 13, 2006
}

\begin{abstract}
The effects of particle composition on heterogeneous catalysis were studied using dendrimer-encapsulated nanoparticles (DENs) as precursors to supported $\mathrm{Pt}-\mathrm{Cu}$ catalysts. Bimetallic $\mathrm{Pt}-\mathrm{Cu}$ DENs with varying $\mathrm{Pt} / \mathrm{Cu}$ ratios were prepared in an anaerobic aqueous solution and deposited onto a high-purity commercial alumina support. The dendrimer template was then thermally removed to yield supported nanoparticle catalysts, which were studied with toluene hydrogenation and $\mathrm{CO}$ oxidation catalysis as well as infrared spectroscopy of adsorbed $\mathrm{CO}$. Incorporating $\mathrm{Cu}$ into Pt nanoparticles had opposite effects on the two test reactions. $\mathrm{Cu}$ acted as a mild promoter for $\mathrm{CO}$ oxidation catalysis, and the promoting effect was independent of the amount of $\mathrm{Cu}$ present. Conversely, $\mathrm{Cu}$ acted as a strong poison for toluene hydrogenation catalysis, and the normalized rate tracked inversely with $\mathrm{Cu}$ content. Infrared spectroscopy of the supported nanoparticles indicated that electronic effects (electron donation from $\mathrm{Cu}$ to $\mathrm{Pt}$ ) were minimal for these materials. Consequently, the catalysis results are interpreted in terms of potential structural differences as a function of $\mathrm{Cu}$ incorporation and reaction conditions.
\end{abstract}

\section{Introduction}

Highly dispersed supported metal nanoparticle catalysts are an important class of industrial materials, as one-third of material U. S. gross national product involves a catalytic process somewhere in the production chain. ${ }^{1}$ State of the art heterogeneous catalysts often contain dopant metals, which are incorporated to promote a desired reaction, prevent undesirable side reactions, or enhance catalyst longevity. ${ }^{2,3}$ Traditional preparative routes involve impregnating metal salts onto high-surfacearea supports, followed by various thermal activation steps. ${ }^{3}$ Most important industrial supports can also be employed as separation media; consequently, chromatographic separation of salt precursors as they pass through the support pore structure is unavoidable. Further, nanoparticle preparation via traditional routes depends on the surface (and even gas phase) mobility of the species present during the thermal treatments., ${ }^{4,5}$ These processes vary widely for different metals and are poorly understood, at best. ${ }^{4,5}$ Consequently, bimetallic materials prepared by such methods are often complicated, have significant compositional inhomogenaity from one particle to the next, and are difficult to characterize.

Recent advances in computational methods are beginning to shed light onto the fundamental properties of bimetallic catalyst systems, and predictive models are beginning to emerge. ${ }^{6-9}$ The potential to controllably tune catalyst properties through the nanoscale design of bimetallic nanoparticles is becoming apparent, and designed bimetallic catalysts with novel behavior for important reactions already appear in the recent literature. ${ }^{10-12}$ However, the utilization of traditional preparative techniques and the complicated materials that arise from these methods remain a significant hurdle to studying new catalysts, evaluating the important features in the best catalysts, and understanding how reactions occur over new materials.

To address these fundamental issues, preparation methods for new model catalysts and appropriate control materials are

* Author to whom correspondence should be addressed. Phone: (210) 999-7557. Fax: (210) 999-7569. E-mail: bert.chandler@trinity.edu. needed. Inorganic and organometallic cluster compounds have been used to successfully prepare novel bimetallic catalysts, ${ }^{5}$ particularly for metal combinations that are thermodynamically unstable in the bulk. ${ }^{13,14}$ The difficulties in cluster preparation, lack of suitable and extensive cluster libraries, and propensity for clusters to fragment, however, have limited their application to relatively few metal systems. ${ }^{15}$

Recent advances in nanoparticle preparation techniques offer new opportunities for the preparation of model catalysts. ${ }^{16-18}$ In this process, surface protected mono- or bimetallic nanoparticles are prepared in solution using colloid stabilizers, deposited onto a support, and the stabilizing agents are removed. This method results in a material composed of supported nanoparticles with known, characterizable, and reproducible synthetic histories. Recent studies from the Nuzzo ${ }^{19}$ and Zhong ${ }^{20}$ labs have shown that the thermodynamic stabilities associated with bulk alloys may be significantly less important at the nanometer scale. Through the use of different preparative methods, both of these research groups have prepared nanoparticles with compositions throughout bulk miscibility gaps. These developing techniques make the controlled study of particle composition effects on catalysis an attainable goal. Additionally, heterogeneous catalysis and catalyst characterization techniques, which directly probe particle surface chemistry, can be considered as underutilized tools for investigating nanoparticle properties. Application of these techniques and comparison to previously studied catalytic systems may provide new insights into the fundamental structural and electronic properties of bimetallic nanoparticles.

\section{Background}

Polyamidoamine (PAMAM) dendrimer-encapsulated nanoparticles (DENs) are attractive potential precursors for model heterogeneous catalysts. PAMAM dendrimers are versatile synthetic hosts, as they have been used to template a variety of metal and semiconductor nanoparticles on the order of $1-3$ $\mathrm{nm} .{ }^{21}$ By varyiation of the dendrimer generation and metal/ 


\section{SCHEME 1}

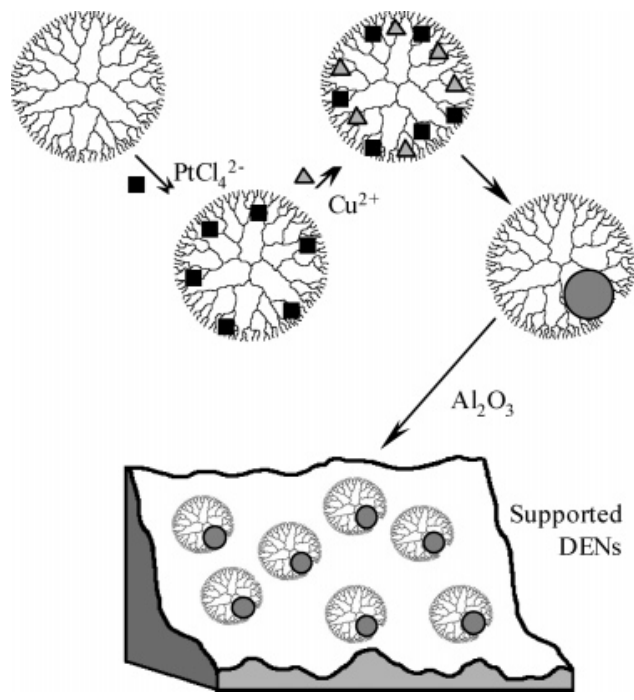

dendrimer ratio, it is possible to control the size of the resulting nanoparticles, which are essentially trapped within the dendrimer framework. ${ }^{18}$ Through the use of appropriate synthetic techniques, in some cases it is even possible to selectively prepare bimetallic DENs with well-mixed or core-shell morphologies. ${ }^{18}$

The solution chemistry of DENs and their application as solution phase catalysts was recently reviewed by Crooks and co-workers. ${ }^{18}$ Homogeneous catalysis by bimetallic DENs is of particular relevance to the present work. To our knowledge, the only reports of homogeneous catalysis by bimetallic DENs come from the Crooks and Rhee groups dealing with the $\mathrm{PtPd},{ }^{22,23} \mathrm{PdRh},{ }^{24}$ and $\mathrm{PdAu}^{25}$ metal systems. In all of these studies, synergy in catalytic activity was observed. The complete studies of hydrogenation catalysis by PtPd DENs show that the synergy is expressed through most of the composition regime but is most pronounced for Pd-rich nanoparticles. ${ }^{22,23}$

PAMAM DENs are readily immobilized on a variety of solid substrates. Supported or immobilized DENs can also be active catalysts or electrocatalysts, provided an appropriate solvent is present. ${ }^{18,26}$ In the absence of a solvent, however, supported intact DENs are inactive catalysts and do not bind CO. After being dried, the organic dendrimer apparently collapses onto the nanoparticle, poisoning the metal surface. ${ }^{26-28}$ Because the amide architecture is relatively unstable at elevated temperatures, ${ }^{29,30}$ DENs can be "activated" by heating under oxidizing and/or reducing atmospheres to remove the organic template. ${ }^{27}$ Provided activation temperatures are moderate (ca. $300{ }^{\circ} \mathrm{C}$ ), relatively clean nanoparticle surfaces can be prepared without substantial agglomeration, and the resulting monometallic materials have proven to be good models for traditionally prepared catalysts. ${ }^{27,31}$ Only two previous reports employ bimetallic DENs to prepare supported nanoparticle catalysts: our work with the $\mathrm{Pt}-\mathrm{Au}$ system ${ }^{32}$ and Crooks' work with $\mathrm{Pd}-$ $\mathrm{Au}$ catalysts. ${ }^{33}$ Both papers report catalytic synergism arising from the intimate mixing of two metals; however, both studies were limited to a single bimetallic particle composition.

In this work, we extend this general preparative route for heterogeneous catalysts to the $\mathrm{Pt}-\mathrm{Cu}$ system (Scheme 1) and report the first study varying heterogeneous catalyst composition using DENs as catalyst precursors. Coincident with these goals is the desire to begin learning how to tune nanoparticle properties and reactivity through the controlled addition of dopant metals. Additionally, we seek to begin developing methods of rationally and systematically testing theoretical models for bimetallic catalyst systems.
The $\mathrm{Pt}-\mathrm{Cu}$ system is a good choice for initial investigations into composition effects because the two metals are miscible through the entire composition range. ${ }^{34}$ Additionally, the system has been well studied and characterized, and there is current interest in its reactivity for dehydrodehalogenation, ${ }^{35,36}$ dehydrogenation, ${ }^{37}$ and nitrate reduction ${ }^{38}$ reactions. The system is synthetically accessible for DENs, as hydroxyl-terminated PAMAM dendrimers have previously been used to template monometallic $\mathrm{Pt}$ and $\mathrm{Cu}$ nanoparticles. ${ }^{18,21}$ Dendrimer uptake of the aqueous forms of both $\mathrm{PtCl}_{4}{ }^{2-}$ and $\mathrm{Cu}^{2+}$ has been previously studied with UV-vis spectroscopy, and the uptake limits (metal ions per dendrimer) and qualitative adsorption kinetics are well documented for each metal. ${ }^{18,21}$

\section{Experimental Section}

Materials. Nanopure water was used for all solutions. Hydroxyl-terminated generation 5 starburst polyamidoamine (PAMAM) dendrimers (G5-OH) were obtained as a 5\% solution in methanol (Aldrich). The methanol was removed by rotary evaporation at room temperature; the resulting oil was diluted to a concentration of $0.01 \mathrm{mM}$ with water. $\mathrm{K}_{2} \mathrm{PtCl}_{4}, \mathrm{NaBH}_{4}$, and $\mathrm{Cu}\left(\mathrm{NO}_{3}\right)_{2}$ were obtained from Aldrich and used without further purification. Alumina (Puralox HP 14/150, surface area $=150 \mathrm{~m}^{2} / \mathrm{g}$ ) was generously provided by Sasol North America, Inc. $\mathrm{O}_{2}, \mathrm{H}_{2}, \mathrm{He}, \mathrm{N}_{2}$, and Ar were all UHP grade from Airgas. Carbon monoxide (99.8\% in aluminum cylinder) was purchased from Matheson Trigas.

Metal Uptake by G5-OH Dendrimers. UV-vis spectra during dendrimer-metal complexation were collected using an Ocean Optics, Inc. high-resolution fiber optic spectrometer (HR2000CG UV-NIR). For $\mathrm{Pt}^{2+}$ uptake by G5-OH PAMAM dendrimer, $10 \mathrm{~mL}$ of $0.01 \mathrm{mM}$ dendrimer solution was mixed in a round-bottom flask with sufficient $5 \mathrm{mM} \mathrm{K}_{2} \mathrm{PtCl}_{4}$ to prepare the following Pt/dendrimer ratios: 30:1, 23:1, and 15:1. A portion of the solution was transferred to a cuvette and analyzed at various time intervals using $0.01 \mathrm{mM}$ G5-OH PAMAM dendrimer solution as a reference. After 4 days the $\mathrm{pH}$ was increased to 7 .

For $\mathrm{Cu}$ uptake by $\mathrm{G} 5-\mathrm{OH}, 10 \mathrm{~mL}$ of $0.01 \mathrm{mM}$ dendrimer solution was mixed in a round-bottom flask with sufficient 5 $\mathrm{mM} \mathrm{Cu}\left(\mathrm{NO}_{3}\right)_{2}$ to result in the following $\mathrm{Cu} /$ dendrimer ratios: $30: 1,23: 1$, and 15:1. An aliquot of the solution was immediately transferred to a cuvette for UV-vis spectroscopic analysis. A spectrum was obtained every $3 \mathrm{~min}$ for $30 \mathrm{~min}$, and the $\mathrm{pH}$ was increased to 7.

For $\mathrm{Cu}$ uptake by the $\mathrm{Pt}$-dendrimer complex, $10 \mathrm{~mL}$ of 0.01 $\mathrm{mM}$ dendrimer solution was mixed in a round-bottom flask with sufficient $5 \mathrm{mM} \mathrm{K}_{2} \mathrm{PtCl}_{4}$ to result in the following Pt/dendrimer ratios: 30:1, 23:1, and 15:1. The solutions were stirred for 2 days, and the $\mathrm{Cu}$ uptake procedure was followed using sufficient $5 \mathrm{mM} \mathrm{Cu}\left(\mathrm{NO}_{3}\right)_{2}$ to result in a metal/dendrimer ratio of $45: 1$ for all solutions.

Preparation of Supported Nanoparticles. The DENs were prepared based on techniques detailed in the literature. ${ }^{21}$ Approximately $10 \mathrm{~mL}$ of $0.01 \mathrm{mM}$ dendrimer solution was mixed in a Schlenk flask with sufficient $5 \mathrm{mM} \mathrm{K}_{2} \mathrm{PtCl}_{4}$ to result in the following Pt/dendrimer ratios: 30:1, 23:1, and 15:1. After being stirred for 2 days, the $\mathrm{pH}$ was adjusted to 7-7.5, and sufficient $5 \mathrm{mM} \mathrm{Cu}\left(\mathrm{NO}_{3}\right)_{2}$ was added to bring the total metal/ dendrimer ratio to $45: 1 . \mathrm{N}_{2}$ was bubbled through the solution for $30 \mathrm{~min}$, and subsequent steps were carried out in an inert atmosphere using standard Schlenk techniques.

$\mathrm{NaBH}_{4}$ solution $(0.045 \mathrm{M})$ was degassed, and $1 \mathrm{~mL}$ was added to the flask as $\mathrm{N}_{2}$ was continually bubbled through the 
solution. The solution turned a champagne color as the metals were reduced after stirring for $20 \mathrm{~min}$. The $\mathrm{pH}$ of the solution was then adjusted to 8.5 with $\mathrm{NaOH}$ and $\mathrm{HNO}_{3}$. The alumina support was prepared by degassing $700 \mathrm{mg}$ of $60-80$ mesh alumina in a Schlenk flask for $1 \mathrm{~h}$. The DEN solution was then added to the degassed support via cannula, and the mixture was stirred overnight under $\mathrm{N}_{2}$. The solid gray catalyst was isolated from a colorless solution by vacuum filtration over a medium grain frit, washed with $95 \%$ ethanol, and dried at $80{ }^{\circ} \mathrm{C}$ in a vacuum oven overnight. The supported DENs were activated by exposing the dried catalyst to flowing $\mathrm{O}_{2}$ for $16 \mathrm{~h}$ at 300 ${ }^{\circ} \mathrm{C}$, as described previously..$^{31}$

Pt and Cu Analysis with Atomic Absorption Spectroscopy. $\mathrm{Pt}$ and $\mathrm{Cu}$ loadings were determined with a Varian SpectrAA 220FS atomic absorption spectrometer using an acetylene/air flame, as described previously. ${ }^{32}$ Briefly, the sample was treated with freshly prepared aqua regia. The $\mathrm{pH}$ of the resulting solution was adjusted to $6.0-7.0$ with ammonium hydroxide, condensed, and transferred to a $10 \mathrm{~mL}$ volumetric flask containing sufficient $\mathrm{La}\left(\mathrm{NO}_{3}\right)_{3}$ to yield a final solution of $1 \%$ La. Atomic absorption (AA) standards were prepared from Aldrich AA standard solutions and Nanopure water.

FT-IR Spectroscopy. Spectra were collected using a Thermo Nicolet Nexus 470 spectrometer equipped with a deuterated triglyceride sulfate (DTGS) detector using $2 \mathrm{~cm}^{-1}$ resolution. A water-cooled stainless steel IR flow cell with $\mathrm{NaCl}$ windows was used to hold the pressed catalyst wafer $(18-20 \mathrm{mg})$. The optical bench and beam path (outside the flow cell) were continuously purged with $\mathrm{N}_{2}$. A heating element wrapped around the cell with a thermocouple placed in close proximity to the catalyst sample allowed for in situ heating of samples and collection spectra at different temperatures. All spectra were collected with gases flowing at $60 \mathrm{~mL} / \mathrm{min}$; the gas composition was manipulated using the external manifold.

Previously oxidized catalyst samples underwent in situ reduction $\left(20 \% \mathrm{H}_{2}\right.$ balance $\mathrm{He}$ at $300{ }^{\circ} \mathrm{C}$ for $\left.3 \mathrm{~h}\right)$ followed by flushing with $\mathrm{He}$ for $1 \mathrm{~h}$ at $300{ }^{\circ} \mathrm{C}$. The samples were then cooled under He flow, and a background spectrum was collected at room temperature. A $5 \% \mathrm{CO} / \mathrm{He}$ mixture was then flowed over the sample for $15 \mathrm{~min}$, followed by pure He. IR spectra of $\mathrm{CO}$ adsorbed on the surface were collected once the gas-phase $\mathrm{CO}$ had been removed from the cell. CO desorption was accomplished by heating the sample under He flow.

CO Oxidation Catalysis. The feed and reactor effluent composition was monitored with an SRI 8610C gas chromatograph with a thermal conductivity detector. ${ }^{31}$ Previously oxidized catalyst samples were diluted $10: 1$ with $\alpha-\mathrm{Al}_{2} \mathrm{O}_{3}$ prior to use. Approximately $150 \mathrm{mg}$ of the activated, diluted catalyst was then placed in a single pass plug flow microreactor and inserted into the furnace. The feed composition in the reactor was $1.1 \%$ $\mathrm{CO}, 20 \% \mathrm{O}_{2}$ (balance $\mathrm{He}$ ), and the flow rate was kept constant at $27 \mathrm{~mL} / \mathrm{min}$. Conversion was measured as a function of temperature, and rate data were determined only when the conversion was below $12 \%$.

Toluene Hydrogenation Catalysis. The oxidized catalyst was diluted $20: 1$ by mass with $\alpha-\mathrm{Al}_{2} \mathrm{O}_{3}$. Approximately 300 $\mathrm{mg}$ of the diluted catalyst was loaded into a glass U-tube and reduced in flowing $\mathrm{H}_{2}$. The temperature was ramped $5^{\circ} \mathrm{C} / \mathrm{min}$ to $200{ }^{\circ} \mathrm{C}$ and soaked for $1 \mathrm{~h}$. The temperature was then ramped $5^{\circ} \mathrm{C} / \mathrm{min}$ to $300{ }^{\circ} \mathrm{C}$ and held at that temperature for an additional $1.5 \mathrm{~h}$. The reactor was then cooled to $60{ }^{\circ} \mathrm{C}$ under flowing $\mathrm{H}_{2}$. A $3.2 \%$ toluene in $\mathrm{H}_{2}$ feed was prepared using a two-stage bubbler. The first stage was held at approximately $40{ }^{\circ} \mathrm{C}$, and the second stage was maintained at $23{ }^{\circ} \mathrm{C} .{ }^{39}$
The reaction was monitored using an SRI $8610 \mathrm{C}$ gas chromatograph with a gas automatic sampling valve, $1 \mathrm{~mL}$ sample loop, and flame ionization detector. Products and reactants were quantified using an $\mathrm{SiO}_{2}$ column operated at 260 ${ }^{\circ} \mathrm{C}$. Peak areas were standardized against external calibration solutions of toluene in hexanes and methylcyclohexane in toluene. ${ }^{39}$ Toluene hydrogenation rates were determined at 60 ${ }^{\circ} \mathrm{C}$ by monitoring conversion as a function of flow rate. Flow rates were measured with a bubble flow meter immediately prior to each injection. Plots of conversion versus inverse space velocity were linear and had $y$-intercepts of $0.02 \%$ or lower.

\section{Results and Discussion}

Nanoparticle and Catalyst Preparation. Because $\mathrm{PtCl}_{4}{ }^{2-}$ uptake is slow (1-2 days) relative to $\mathrm{Cu}^{2+}$ (seconds), we used sequential binding of $\mathrm{PtCl}_{4}{ }^{2-}$ followed by $\mathrm{Cu}^{2+}$ to load generation 5 PAMAM dendrimers $(\mathrm{G} 5-\mathrm{OH})$ with metal precursors (Scheme 1). Most previous studies with these metaldendrimer systems used G4-OH dendrimers, so the use of G5$\mathrm{OH}$ dendrimers in the present study may have moderate effects on the kinetics of metal uptake. Additionally, metal-dendrimer interactions with one precursor may affect the binding of the second when preparing bimetallic nanoparticles.

Accordingly, the individual metal binding steps in Scheme 1 were monitored with $\mathrm{UV}-$ vis spectroscopy. $\mathrm{PtCl}_{4}{ }^{2-}$ uptake by $\mathrm{G} 5-\mathrm{OH}$, monitored by following the disappearance of the $\mathrm{Pt}-$ $\mathrm{Cl}$ charge transfer band at $380 \mathrm{~nm}$, was complete in approximately $24 \mathrm{~h}$ and did not change after adjusting the solution $\mathrm{pH}$ to 7 (spectra in the Supporting Information). Changes in the $380 \mathrm{~nm}$ band were concurrent with changes in a dendrimerbased UV band at $320 \mathrm{~nm}$ indicating uptake into the dendrimer interior. ${ }^{21}$ Copper uptake was fast and consistent with previous reports, even when $\mathrm{Pt}(\mathrm{II})$ complexes had been previously loaded into the dendrimers. Increasing the solution $\mathrm{pH}$ to 7 increased the $\mathrm{Cu}^{2+}$ capacity of $\mathrm{G} 5-\mathrm{OH}$, as Murphy's group has observed. ${ }^{40}$

With the UV-vis experiments as a guide, nanoparticle solutions were prepared by first complexing $\mathrm{PtCl}_{4}{ }^{2-}$ to $\mathrm{G} 5-\mathrm{OH}$ for 2 days. After $\mathrm{Cu}\left(\mathrm{NO}_{3}\right)_{2}$ addition, the solution was adjusted to $\mathrm{pH} 7.0$ and purged with $\mathrm{N}_{2}, \mathrm{NaBH}_{4}$ was added, and the flask was stirred for $24 \mathrm{~h}$. Ratios of $\mathrm{PtCl}_{4}{ }^{2-}$ and $\mathrm{Cu}^{2+}$ to $\mathrm{G} 5-\mathrm{OH}$ were adjusted to maintain a total metal/dendrimer stoichiometry of approximately $45: 1$, which was the maximum $\mathrm{Cu}^{2+}$ loading for G5-OH. The resulting dendrimer-encapsulated nanoparticles (DENs) were deposited onto a commercial alumina support by spontaneous adsorption from aqueous solution. ${ }^{32}$ Support masses were adjusted so that the surface concentration of DENs, and therefore the total number of nanoparticles per gram of catalyst, remained constant. The supported DENs were then dried and oxidized under flowing $\mathrm{O}_{2}$ at $300{ }^{\circ} \mathrm{C}$ for $16 \mathrm{~h}$. Our previous work has shown this activation treatment to be the most effective means of removing dendrimers and organic residues from $\mathrm{Pt}$ based nanoparticles without causing substantial agglomeration. ${ }^{31}$

Catalyst Characterization. The activated supported nanoparticles were characterized by infrared spectroscopy of adsorbed $\mathrm{CO}$, atomic absorption spectroscopy, and transmission electron microscopy (TEM). Characterization data for the catalysts are summarized in Table 1 . The AA data indicate that the stoichiometries set in nanoparticle syntheses are generally carried through to the ultimate catalyst. All of the bimetallic catalysts have $\mathrm{Pt}$ contents slightly lower than the expected values, which was an unexpected result. $\mathrm{Cu}^{0} \mathrm{DENs}$ are relatively unstable and oxidize to $\mathrm{Cu}^{2+}$ by air over several hours, ${ }^{21}$ so $\mathrm{Cu}$ losses to the solution initially seemed more likely. The low $\mathrm{Pt}$ content indicates that $\mathrm{Cu}$ loss due to reoxidation in solution is not a major problem. 
TABLE 1: Summary of Catalyst Characterization Data

\begin{tabular}{lcccc}
\hline catalyst & $\% \mathrm{Pt}$ & $\mathrm{Pt} / \mathrm{Cu}^{a}$ & $\begin{array}{c}\text { high-coverage } \nu_{\mathrm{CO}} \\
\left(\mathrm{cm}^{-1}\right)\end{array}$ & $\begin{array}{c}\text { low-coverage } v_{\mathrm{CO}} \\
\left(\mathrm{cm}^{-1}\right)\end{array}$ \\
\hline $\mathrm{Pt}_{45}$ & 0.19 & & 2075 & 2062 \\
$\mathrm{Pt}_{30} \mathrm{Cu}_{15}$ & 0.17 & 1.7 & 2064 & 2049 \\
$\mathrm{Pt}_{23} \mathrm{Cu}_{23}$ & 0.12 & 0.85 & 2060 & 2046 \\
$\mathrm{Pt}_{15} \mathrm{Cu}_{30}$ & 0.057 & 0.43 & 2060 & $<2050^{b}$
\end{tabular}

${ }^{a}$ Determined via AA spectroscopy. ${ }^{b}$ Value not determined due to rapid $\mathrm{CO}$ desorption and low $\mathrm{Pt}$ loadings.

The consistent relative excess of $\mathrm{Cu}$ in the final materials also indicates that complexation of $\mathrm{Pt}(\mathrm{II})$ species to the dendrimer interior may not be complete in $48 \mathrm{~h}$ or that $\mathrm{Cu}^{2+}$ may displace some of the $\mathrm{Pt}(\mathrm{II})$ species within the dendrimer. Our study is consistent with studies from other labs in that UVvis spectra of mixtures of $\mathrm{PtCl}_{4}{ }^{2-}$ and PAMAM dendrimers cease to change after approximately 2 days. ${ }^{21,28,41,42}$ However, detailed ${ }^{195} \mathrm{Pt}$ NMR studies by Murphy and co-workers indicate that as many as 10 days may be required to equilibrate the various aqueous $\mathrm{Pt}(\mathrm{II})$ species with dendrimer amine groups. ${ }^{41}$ Our current results are also consistent with Ploehn's studies, which indicate that, during borohydride reduction, Pt species are particularly mobile and can escape dendrimer interiors. ${ }^{42}$

Transmission electron microscopy studies of these samples are complicated by the difficulties in obtaining sufficient contrast with the support and the relatively low electron density of $\mathrm{Cu}$. This limits our ability to resolve particles smaller than approximately $3 \mathrm{~nm}$ and makes quantitative analysis of the TEM data unreliable. We did not observe large particles $(>3 \mathrm{~nm})$, which indicates that widespread particle agglomeration during dendrimer thermolysis does not occur. Elemental analysis (vide supra) confirms the bulk presence of $\mathrm{Pt}$ and $\mathrm{Cu}$ in appropriate ratios for all three bimetallic catalysts, but we are unable to draw any meaningful conclusions regarding potential differences in the size and composition of individual particles.

Infrared Spectroscopy of Adsorbed CO. Infrared spectra of $\mathrm{CO}$ adsorbed on the activated catalysts, shown in Figure 1, provide convincing evidence for intimate mixing of $\mathrm{Pt}$ and $\mathrm{Cu}$ in bimetallic nanoparticles. Peak maxima from the IR spectroscopy data are also compiled in Table 1, where comparisons can readily be made. $\mathrm{CO}$ adsorbed on the monometallic $\mathrm{Pt}_{45}$ catalyst exhibited a high-coverage $v_{\mathrm{CO}}$ near $2075 \mathrm{~cm}^{-1}$. The lowcoverage $v_{\mathrm{CO}}$, obtained as the last discernible spectrum at the end of the thermal desorption experiments, was $2062 \mathrm{~cm}^{-1}$. Both of these values are consistent with studies of other supported Pt catalysts prepared from DENs and with traditionally prepared Pt catalysts. ${ }^{27,28,31}$ All of the bimetallic catalyst spectra (Figure 1) were red-shifted $10-15 \mathrm{~cm}^{-1}$ from the high-coverage value. Infrared spectra attributable to $\mathrm{CO}$ bound to $\mathrm{Cu}$ sites $\left(v_{\mathrm{CO}}\right.$ between 2180 and $2100 \mathrm{~cm}^{-1}$ ) were not observed, indicating that surface $\mathrm{Cu}$ is present as $\mathrm{Cu}^{0}$ (vide infra).

Evaluations of structural and electronic effects and their potential impact on catalytic activity are of fundamental interest and importance. $\mathrm{CO}$ adsorption studies are an important tool in evaluating these effects, as both can impact observed $\mathrm{CO}$ stretching frequencies. The absence of $\mathrm{Cu}-\mathrm{CO}$ stretching frequencies provides important indirect information regarding the state of $\mathrm{Cu}$ in the catalysts. $\mathrm{CO}$ is relatively unstable and easily removed from fully reduced $\mathrm{Cu}$ surfaces (i.e., during the He flush required to remove gas-phase $\mathrm{CO}$ ) yet is stable at ambient temperatures when adsorbed on cationic $\mathrm{Cu}$ species. ${ }^{43}$ Consequently, the lack of higher-energy stretching frequencies (ca. 2140-2110 $\mathrm{cm}^{-1}$ ) eliminates the possibility that cationic $\mathrm{Cu}$ surface species are present and indicates that $\mathrm{Cu}$ is fully reduced by the hydrogen treatment. Previous studies with zeolite

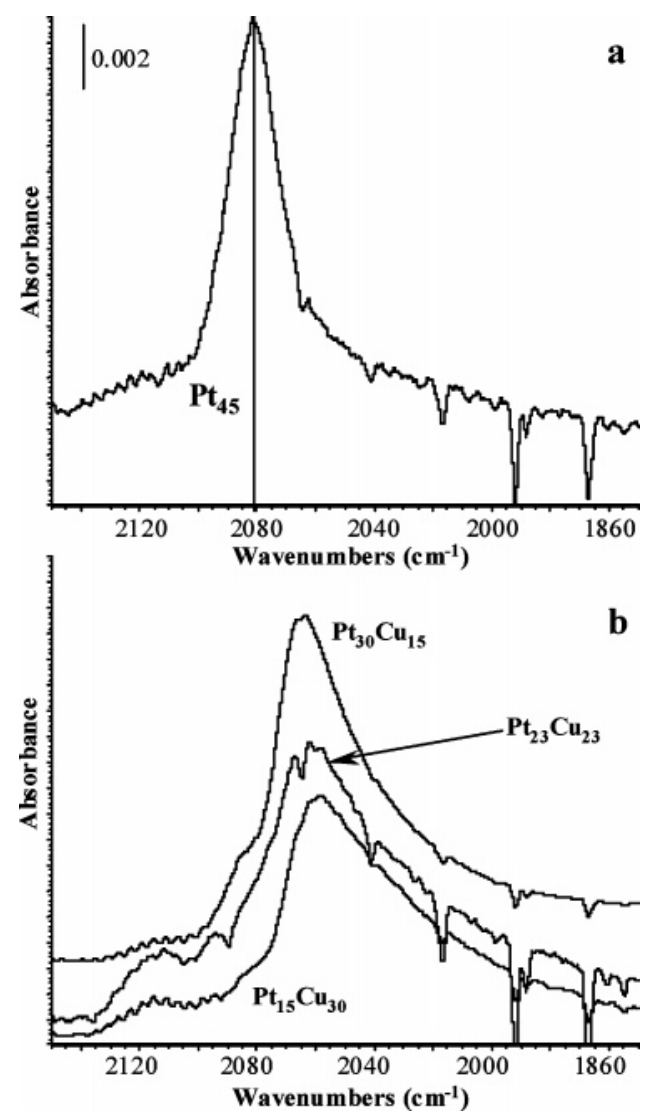

Figure 1. Infrared spectra of $\mathrm{CO}$ adsorbed on (a) $\mathrm{Pt}_{45}$ and (b) $\mathrm{Pt}_{30^{-}}$ $\mathrm{Cu}_{15}, \mathrm{Pt}_{23} \mathrm{Cu}_{23}$, and $\mathrm{Pt}_{15} \mathrm{Cu}_{30}$.

supported $\mathrm{Pt}-\mathrm{Cu}$ catalysts indicate that $\mathrm{Pt}$ helps catalyze the reduction of $\mathrm{Cu}$, so this result is not surprising. ${ }^{43}$

The absence of observable $\mathrm{Cu}-\mathrm{CO}$ bands indicates that oxidized surface $\mathrm{Cu}$ species are not present but provides relatively little direct information regarding particle surface composition. The relatively large $\mathrm{Pt}-\mathrm{CO}$ bands for the bimetallic materials suggest that, at least in the presence of $\mathrm{CO}$, the nanoparticle surfaces are enriched in $\mathrm{Pt}$. $\mathrm{Pt}-\mathrm{CO}$ bonds are substantially stronger than $\mathrm{Pt}-\mathrm{Cu}$, which provides a strong driving force for drawing Pt to the surface. This effect has been previously reported for traditionally prepared $\mathrm{Pt}-\mathrm{Cu}$ catalysts and dendrimer-templated $\mathrm{Pt}-\mathrm{Au}$ nanoparticles. ${ }^{32,36}$ Computational models have also predicted the presence and stability of subsurface $\mathrm{Cu}$ for $\mathrm{Pt}-\mathrm{Cu}$ alloys, based on d-band spacing and lattice compression effects. ${ }^{6-9}$ The relative instability of $\mathrm{Cu}^{0}-$ $\mathrm{CO}$ species, however, precludes us from drawing any further conclusions regarding the surface composition or possible trends in surface composition as a function of particle composition.

The shifts in $\mathrm{Pt}-\mathrm{CO}$ stretching frequencies are attributable to a combination of electronic and dipole-dipole coupling effects. Electronic effects arise from a net (partial) electron donation from $\mathrm{Cu}$ to the more electronegative Pt. This enhances population of $\mathrm{Pt} \mathrm{d}$-bands (relative to a pure $\mathrm{Pt}$ material), increasing $\mathrm{CO}$ back-bonding and resulting in a lower $\mathrm{CO}$ stretching frequency. Dipole-dipole coupling, which is thoughspace interaction between adsorbed dipoles vibrating at the same frequency ( $\mathrm{Pt}-\mathrm{CO}$ adsorbates), also plays an important role in $\mathrm{CO}$ stretching frequencies on supported catalysts. Increased dipole coupling, which occurs when vibrating dipoles are close to one another, causes a blue shift in the observed CO stretching frequency. Consequently, as one metal dilutes another, dipole coupling effects are diminished, and a resulting red shift is observed in the $\mathrm{CO}$ stretching frequency. 
TABLE 2: Summary of Catalytic Activity Data

\begin{tabular}{lcccc}
\hline & \multicolumn{2}{c}{ CO oxidation } & & toluene hydrogenation \\
\cline { 2 - 3 } catalyst & rate @ $60{ }^{\circ} \mathrm{C}^{a}$ & $E_{\text {app }}^{b}(\mathrm{~kJ} / \mathrm{mol})$ & & rate @ $60{ }^{\circ} \mathrm{C}^{c}$ \\
\hline $\mathrm{Pt}_{45}$ & 180 & 67 & & 1300 \\
$\mathrm{Pt}_{30} \mathrm{Cu}_{15}$ & 350 & 46 & & 460 \\
$\mathrm{Pt}_{23} \mathrm{Cu}_{23}$ & 360 & 49 & & 230 \\
$\mathrm{Pt}_{15} \mathrm{Cu}_{30}$ & 370 & 47 & & $<5$
\end{tabular}

${ }^{a}$ Units of $\mathrm{mol} \mathrm{CO} /(\mathrm{mol} \mathrm{Pt} / \mathrm{min}) \times 10^{3} .{ }^{b}$ Apparent activation energies from Arrhenius plots $(\mathrm{kJ} / \mathrm{mol}) .{ }^{c}$ Units of $\mathrm{mol} \mathrm{CO} /(\mathrm{mol} \mathrm{Pt} / \mathrm{min}) \times 10^{3}$.

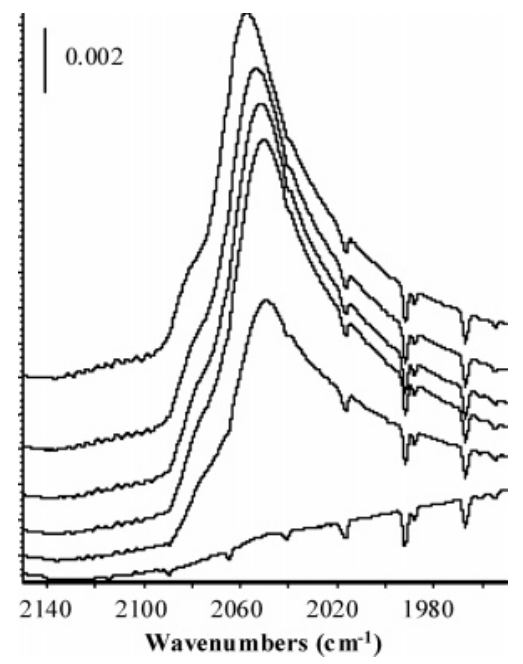

Figure 2. Infrared spectra during thermal $\mathrm{CO}$ desorption from $\mathrm{Pt}_{30^{-}}$ $\mathrm{Cu}_{15}$.

To evaluate the relative importance of dipole coupling effects, low-coverage $\mathrm{CO}$ stretching frequencies (Table 1) were determined from thermal desorption experiments. A representative desorption experiment with $\mathrm{Pt}_{30} \mathrm{Cu}_{15}$ is shown in Figure 2. The low-coverage $\mathrm{CO}$ stretching frequencies of the bimetallic catalysts were consistently lower than the low-coverage $\mathrm{CO}$ spectrum on Pt. The bimetallic samples also had decreasing lowcoverage $\mathrm{CO}$ stretching frequencies as $\mathrm{Cu}$ content increased, although the differences between bimetallic samples were relatively small. Since thermal desorption experiments may only reduce, but not completely eliminate, surface dipole coupling, it is possible that some coupling persists in the highertemperature spectra. D'Itri and co-workers' work with silica supported with $\mathrm{Pt}$ and $\mathrm{Pt}-\mathrm{Cu}$ catalysts indicated relatively small electronic effects for $\mathrm{Cu}$-rich $\mathrm{Pt}-\mathrm{Cu}$ alloys and no electronic effects for equal molar $\mathrm{Pt}-\mathrm{Cu}$ materials. ${ }^{36}$ Consequently, although we cannot completely rule out the presence of electronic effects, the present data indicate that any electronic effects present in these materials are likely to be mild.

Catalytic Test Reactions. Catalytic activity of the supported nanoparticles was evaluated with the toluene hydrogenation and $\mathrm{CO}$ oxidation test reactions. Toluene hydrogenation activities, collected in Table 2, were determined from the slopes of plots of $\%$ methylcyclohexane in the reactor effluent versus $1 /$ flow (i.e., inverse space velocity plots). These plots, shown in Figure 3 , were always linear for conversions at or below $1 \%$. The small nonzero intercepts are due to the presence of a small impurity in the toluene (HPLC grade). The $\mathrm{Cu}$-only control material, $\mathrm{Cu}_{45}$, was inactive for toluene hydrogenation under the reaction conditions and is omitted for clarity. Since $\mathrm{Cu}$ was inactive for the reaction, catalytic rates were normalized per total mole of $\mathrm{Pt}$ in the catalyst.

The data in Figure 3 and Table 2 show that $\mathrm{Cu}$ incorporation has a substantial poisoning effect on hydrogenation catalysis by Pt. Further, the suppression of hydrogenation activity directly

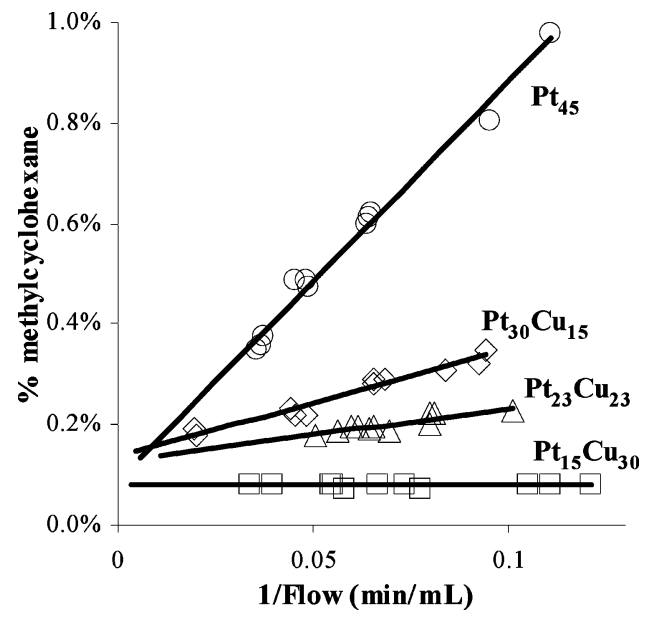

Figure 3. Toluene hydrogenation catalysis. Plots of conversion vs 1/flow for $\mathrm{Pt}_{45}, \mathrm{Pt}_{30} \mathrm{Cu}_{15}, \mathrm{Pt}_{23} \mathrm{Cu}_{23}$, and $\mathrm{Pt}_{15} \mathrm{Cu}_{30}$. Catalytic activities are proportional to the slope of each line.

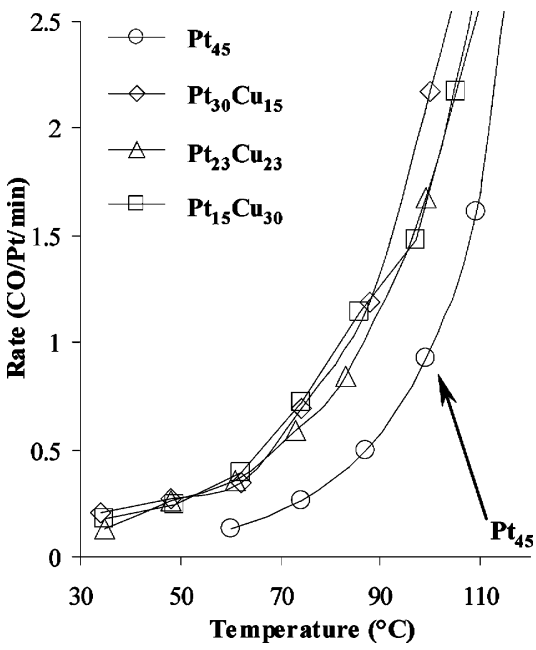

Figure 4. $\mathrm{CO}$ oxidation catalysis. Rate $(\mathrm{mol} \mathrm{CO} /(\mathrm{mol} \mathrm{Pt} / \mathrm{min}))$ vs temperature plots for $\mathrm{Pt}_{45}, \mathrm{Pt}_{30} \mathrm{Cu}_{15}, \mathrm{Pt}_{23} \mathrm{Cu}_{23}$, and $\mathrm{Pt}_{15} \mathrm{Cu}_{30}$.

correlates with the $\mathrm{Cu}$ content set in the initial nanoparticle synthesis. Incorporating one-half of an equivalent of $\mathrm{Cu}$ into the nanoparticles decreases the nominal rate per mole of Pt by almost one-third; 2 equiv of $\mathrm{Cu}$ effectively shut off toluene hydrogenation activity.

$\mathrm{CO}$ oxidation activity data for the Pt-containing catalysts is shown in Figure 4. As with toluene hydrogenation catalysis, the $\mathrm{Cu}_{45}$ material was inactive for $\mathrm{CO}$ oxidation, and all rates are normalized to the total moles of Pt present. In contrast to the toluene hydrogenation results, the data in Figure 4 show that $\mathrm{Cu}$ acts as a mild promoter for $\mathrm{CO}$ oxidation when it is incorporated into Pt nanoparticles. Arrhenius plots of the activity data, shown in Figure 5 and organized in Table 2, show that $\mathrm{Cu}$ incorporation also slightly lowers the apparent activation energy $\left(E_{\text {app }}\right)$ for this reaction. The effects of $\mathrm{Cu}$ incorporation do not scale with the amount of $\mathrm{Cu}$ present; rather for $\mathrm{CO}$ oxidation, the effect is determined by the presence or absence of $\mathrm{Cu}$.

Structural and Electronic Effects on Catalytic Activity. It is appropriate and important to reconcile the divergent effects of $\mathrm{Cu}$ incorporation on the two test reactions, particularly since they are opposite in both direction and magnitude (mild promotion of $\mathrm{CO}$ oxidation that is independent of $\mathrm{Cu}$ content versus strong inhibition of toluene hydrogenation that is $\mathrm{Cu}-$ dependent). Structural and electronic factors can affect the catalytic activity for these oxidation-reduction reactions. Pt is 


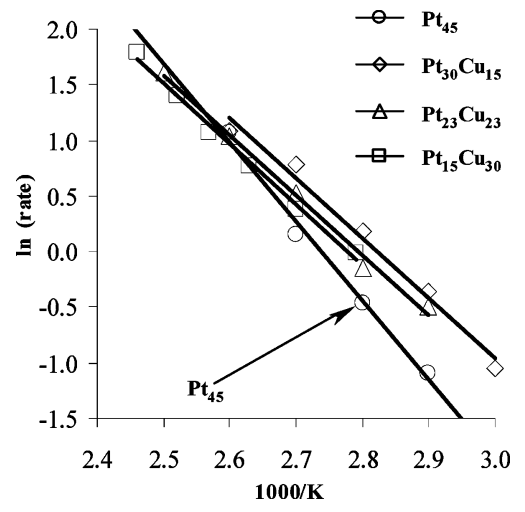

Figure 5. $\mathrm{CO}$ oxidation catalysis. Arrhenius plots for $\mathrm{Pt}_{45}, \mathrm{Pt}_{30} \mathrm{Cu}_{15}$, $\mathrm{Pt}_{23} \mathrm{Cu}_{23}$, and $\mathrm{Pt}_{15} \mathrm{Cu}_{30}$.

slightly more electronegative than $\mathrm{Cu}$, so it is possible that the more active metal is enriched in electron density upon incorporation of $\mathrm{Cu}$. However, the electronegativity difference is small (2.2 vs 1.9), and the IR spectroscopy data indicate that any electronic differences between the mono- and bimetallic catalysts are correspondingly mild. The low-coverage $\mathrm{Pt}-\mathrm{CO}$ stretching frequencies show only a weak trend with $\mathrm{Cu}$ incorporation, but the shifts are fairly small and are in the range of singleton $\mathrm{Pt}-\mathrm{CO}$ stretching frequencies for monometallic $\mathrm{Pt}$ catalysts. Although these small potential electronic effects might be a reasonable explanation for the copper's promotion of $\mathrm{CO}$ oxidation catalysis (vide infra), we do not believe that they are sufficient to explain the 100-fold decrease in Pt activity for toluene hydrogenation.

The trend in hydrogenation activity tracks directly with the metal stoichiometry, which is set and controlled in the initial nanoparticle synthesis. This reduction in catalytic activity with increasing $\mathrm{Cu}$ content is likely due to surface enrichment in copper under a reducing atmosphere. $\mathrm{Cu}$ surface enrichment in this system been postulated for a number of traditionally prepared supported $\mathrm{Pt}-\mathrm{Cu}$ catalysts, particularly under reducing atmospheres. ${ }^{36-38,43}$ Copper has a lower work function (heat of sublimation) than platinum, ${ }^{34}$ indicating generally weaker interatomic bonding for the coinage metal. As a result, $\mathrm{Pt}$ is expected to cluster at the center of the nanoparticle to maximize the stronger $\mathrm{Pt}-\mathrm{Pt}$ metal bonding, leaving $\mathrm{Cu}$ atoms more stable at the particle surface. A recent study by Rioux and Vannice carefully showed this effect, as increasing the $\mathrm{Cu}$ content of $\mathrm{Pt}-\mathrm{Cu} / \mathrm{C}$ catalysts reduced the number of surface $\mathrm{Pt}$ atoms and yielded bimetallic catalysts kinetically similar to $\mathrm{Cu} .{ }^{37}$

At the same time, the $\mathrm{CO}$ adsorption data show a substantial amount of $\mathrm{Pt}$ on the surfaces of even the $\mathrm{Pt}_{15} \mathrm{Cu}_{30}$ particles. This is likely due to the fluxional nature that has been suggested for $\mathrm{Pt}$ nanoparticles ${ }^{44}$ and a CO-induced redistribution of the two metals. Pt forms much stronger surface bonds with $\mathrm{CO}$ than does $\mathrm{Cu}^{0}$, as shown by the instability of the $\mathrm{Cu}-\mathrm{CO}$ species under $\mathrm{He}$ purge. The relative strength of the $\mathrm{Pt}-\mathrm{CO}$ bond provides a driving force for pulling Pt to the particle surface, ${ }^{45}$ and a similar restructuring was concluded to be at work for supported $\mathrm{Pt}-\mathrm{Au}$ nanoparticles prepared as DENs. Additionally, D'Itri and co-workers have invoked a comparable explanation in explaining dehydrohalogenation catalysis by traditionally prepared $\mathrm{Pt}-\mathrm{Cu}$ catalysts. ${ }^{36,46}$

The promotion of $\mathrm{CO}$ oxidation catalysis is more difficult to interpret, since the activity enhancement is effectively the same for all the $\mathrm{Cu}$-containing catalysts and does not scale with $\mathrm{Cu}$ content. The activity data argues that incorporating $\mathrm{Cu}$ into the Pt nanoparticles results in a small fundamental change in the catalytic active site rather than increasing the number of active sites. This conclusion is supported by the consistent and lower Arrhenius activation energies ( $\left.E_{\text {app }}\right)$ for the $\mathrm{Cu}$-containing materials. The current data do not support a conclusion as to how $\mathrm{Cu}$ modifies nanoparticle reactivity, and a combination of structural and electronic modifications might be at work.

The simplest structural explanation is that surface $\mathrm{Cu}$ atoms provide a new type of surface site that binds $\mathrm{CO}$ more weakly than monometallic Pt sites. The $E_{\text {app }}$ values for the bimetallic nanoparticles, which strongly depend on heats of adsorption, are $30 \%$ lower than that of the monometallic Pt catalyst. This explanation is also attractive in light of models for this reaction over Pt, which implicates desorption of a key weakly bound $\mathrm{CO}$-based intermediate as the rate-determining step. Oxygen is also more competitive for binding on $\mathrm{Cu}$ than $\mathrm{Pt}(\mathrm{Cu}-\mathrm{CO}$ bonds are weak, vide supra), so $\mathrm{Cu}$ incorporation may simply increase the amount of surface oxygen available on the particle.

Because $\mathrm{CO}$ binding appears to enrich the surface in $\mathrm{Pt}$, the surface stoichiometry under the reaction conditions is unclear. It is also possible that, in the presence of $\mathrm{CO}$, the bimetallic particles result in Pt-on- $\mathrm{Cu}$ subsurface alloys that have been predicted by some computational models. ${ }^{6-9}$ These subsurface alloys can be activated through electronic influences or structurally through the epitaxial compression of surface Pt atoms. This explanation is consistent with a mild electronic effect on $\mathrm{Pt}$ observed in the infrared spectra. At the same time, correlations between IR spectra and catalytic activity must be drawn with extreme care, since there is no guarantee that the strongly bound $\mathrm{Pt}-\mathrm{CO}$ species observed in the IR are the active species in $\mathrm{CO}$ oxidation catalysis. Additionally, the expected influence of the electronic effect (enhanced metal-ligand back-bonding inferred from a slightly weaker $\mathrm{CO}$ bond) would predict stronger $\mathrm{Pt}-\mathrm{C}$ bonds and is inconsistent with a model involving desorption in the slow step. ${ }^{47}$ Although we cannot rule out an electronic nature of the activity enhancement, we favor structural explanations.

\section{Summary and Conclusions}

PAMAM dendrimers can be used to template bimetallic Pt$\mathrm{Cu}$ nanoparticles with controlled metal stoichiometries in solution. These nanoparticles can be deposited on to a highsurface-area oxide support, and the dendrimer can be thermally removed to yield active supported bimetallic nanoparticle catalysts. Infrared spectroscopy of adsorbed $\mathrm{CO}$ indicated a surface dilution of $\mathrm{Pt}$ in $\mathrm{Cu}$ and suggested only weak electronic donation from $\mathrm{Cu}$ to $\mathrm{Pt}$, if any. Importantly, the stoichiometry set in the initial solution syntheses of the nanoparticles has a direct influence on the activity of the resulting catalysts, thus opening new opportunities for studying particle composition effects for a variety of catalytic reactions.

The incorporation of $\mathrm{Cu}$ into $\mathrm{Pt}$ nanoparticles has opposing effects on $\mathrm{CO}$ oxidation and toluene hydrogenation catalysis. Toluene hydrogenation was suppressed by $\mathrm{Cu}$ addition, and at a $2: 1 \mathrm{Cu} / \mathrm{Pt}$ ratio, the catalysis was effectively shut off. This tuning of catalytic activity is likely due to surface enrichment in $\mathrm{Cu}$, which is inactive for toluene hydrogenation. Incorporating $\mathrm{Cu}$ into the nanoparticles, however, enhanced $\mathrm{CO}$ oxidation catalysis. This enhancement is consistent with the facile exchange of surface and subsurface atoms within individual nanoparticles and can be interpreted in terms of a variety of potential structural and electronic influences.

Acknowledgment. We gratefully acknowledge the Robert A. Welch Foundation (Grant No. W-1552) for financial support of this work. N.N.H. thanks the Welch Foundation's Departmental Grant program (W-0031) for a summer stipend. Ac- 
knowledgment is made to the donors of the American Chemical Society Petroleum Research Fund (Grant No. 37604-GB5) for supporting the purchase and construction of the $\mathrm{CO}$ oxidation reactor system. Finally, we are grateful to Dr. Michael Keung of Sasol North America, Inc. for providing the high-purity commercial alumina support.

Supporting Information Available: UV-vis spectroscopic study of $\mathrm{PtCl}_{4}{ }^{-}$complexation by $\mathrm{G} 5-\mathrm{OH}$ and low-coverage infrared spectra of CO bound to the bimetallic catalysts. This material is available free of charge via the Internet at http:// pubs.acs.org.

\section{References and Notes}

(1) Bell, A. Science 2003, 299, 1688-1691.

(2) Sinfelt, J. H. Bimetallic Catalysts: Discoveries, Concepts, and Applications; John Wiley \& Sons:.New York, 1983.

(3) Catalysis by Metals and Alloys; Ponec, V., Bond, G. C., Eds.; Elsevier: Amsterdam, 1995; Vol. 95

(4) Ponec, V.; Bond, G. C. Catalysis by Metals and Alloys; Studies in Surface Science and Catalysis 95; Elsevier: New York, 1995.

(5) Alexeev, O.; Gates, B. C. Ind. Eng. Chem. Res. 2003, 42, 15711587.

(6) Greeley, J.; Mavrikakis, M. Nat. Mater. 2004, 3, 810-815.

(7) Mavrikakis, M.; Hammer, B.; Nørskov, J. K. Phys. Rev. Lett. 1998, $81,2819-2822$

(8) Neurock, M. J. Catal. 2003, 216, 73-88.

(9) Kitchin, J. R.; Nørskov, J. K.; Barteau, M.; Chen, J. G. J. Chem. Phys. 2004, 120, 10240-10246.

(10) Shabaker, J. W.; Huber, G. W.; Dumesic, J. A. J. Catal. 2004, 222, 180-191.

(11) Huber, G. W.; Shabaker, J. W.; Dumesic, J. A. Science 2003, 300, 2075-2078

(12) Kitchin, J. R.; Khan, N. A.; Barteau, M. A.; Chen, J. G.; Yakshinksiy, B.; Madey, T. E. Surf. Sci. 2003, 544, 295-308.

(13) Chandler, B. D.; Schabel, A. B.; Blanford, C. F.; Pignolet, L. H. J. Catal. 1999, 187, 367-384.

(14) Mihut, C.; Descorme, C.; Duprez, D.; Amiridis, M. D. J. Catal. 2003, 212, 125-135.

(15) Brenner, A. In Metal Clusters; Moskovits, M., Ed.; John Wiley \& Sons: New York, 1986; pp 249-282.

(16) Daniel, M.-C.; Astruc, D. Chem. Rev. 2004, 104, 293-346.

(17) Brust, M.; Kiely, C. J. Colloids Surf., A 2002, 202, 175-186.

(18) Scott, R. W. J.; Wilson, O. M.; Crooks, R. M. J. Phys. Chem. B 2005, 109, 692-704.

(19) Hills, C. W.; Mack, N. H.; Nuzzo, R. G. J. Phys. Chem. B 2003, $107,2626-2636$

(20) Luo, J.; Maye, M. M.; Petkov, V.; Kariuki, N. N.; Wang, L.; Njoki, P.; Mott, D.; Lin, Y.; Zhong, C.-J. Chem. Mater. 2005, 17, 3086-3091.
(21) Crooks, R. M.; Zhao, M.; Sun, L.; Chechik, V.; Yeung, L. K. Acc. Chem. Res. 2001, 34, 181-190.

(22) Chung, Y. M.; Rhee, H. K. Catal. Lett. 2003, 85, 159-164.

(23) Scott, R. W. J.; Datye, A. K.; Crooks, R. M. J. Am. Chem. Soc. 2003, 125, 3708-3709.

(24) Chung, Y. M.; Rhee, H. K. J. Mol. Catal. A: Chem. 2003, 206, 291-298.

(25) Scott, R. W. J.; Wilson, O. M.; Oh, S.-K.; Kenik, E. A.; Crooks, R. M. J. Am. Chem. Soc. 2004, 126, 15583-15591.

(26) Liu, D. X.; Gao, J. X.; Murphy, C. J.; Williams, C. T. J. Phys. Chem B 2004, 108, 12911-12916.

(27) Lang, H.; May, R. A.; Iversen, B. L.; Chandler, B. D. J. Am. Chem. Soc. 2003, 125, 14832-14836.

(28) Deutsch, S. D.; Lafaye, G.; Liu, D.; Chandler, B. D.; Williams, C. T.; Amiridis, M. D. Catal. Lett. 2004, 97, 139-143.

(29) Dendrimers and Other Dendritic Polymers; Fréchet, J. M. J., Tomalia, D. A., Eds.; John Wiley \& Sons: West Sussex, U. K., 2001.

(30) Ozturk, O.; Black, T. J.; Perrine, K.; Pizzolato, K.; Williams, C. T.; Parsons, F. W.; Ratliff, J. S.; Gao, J.; Murphy, C. J.; Xie, H.; Ploehn, H. J.; Chen, D. A. Langmuir 2005, 21, 3998-4006.

(31) Singh, A.; Chandler, B. D. Langmuir 2005, 21, 10776-10782.

(32) Lang, H.; Maldonado, S.; Stevenson, K. J.; Chandler, B. D. J. Am. Chem. Soc. 2004, 126, 12949-12956.

(33) Scott, R. W. J.; Sivadinarayana, C.; Wilson, O. M.; Yan, Z.; Goodman, D. W.; Crooks, R. M. J. Am. Chem. Soc. 2005, 127, 13801381.

(34) van Santen, R. A.; Sachtler, W. M. H. J. Catal. 1974, 33, 202209.

(35) Ito, L. N.; Harley, A. D.; Holbrook, M. T.; Smith, D. D.; Murchison, C. B.; Cisneros, M. D. (Dow Chemical Co.) PCT Int. Appl. WO9407819, 1994.

(36) Borovkov, V. Y.; Luebke, D. R.; Kovalchuk, V.; d'Itri, J. L. J. Phys. Chem. B 2003, 107, 5568-5574.

(37) Rioux, R. M.; Vannice, M. A. J. Catal. 2005, 233, 147-165.

(38) Epron, F.; Gauthard, F.; Barbier, J. Appl. Catal., A 2002, 237, 253261.

(39) Beakley, L.; Yost, S.; Cheng, R.; Chandler, B. D. Appl. Catal., A 2005, 292, 124-129.

(40) Gao, J. Ph.D. Thesis, University of South Carolina, Columbia, SC, 2005

(41) Pellechia, P. J.; Gao, J.; Gu, Y.; Ploehn, H. J.; Murphy, C. J. Inorg. Chem. 2003, 43, 1421-1428.

(42) Gu, Y.; Xie, H.; Gao, J.; Liu, D.; Williams, C. T.; Murphy, C. J.; Ploehn, H. J. Langmuir 2005, 21, 3122-3131.

(43) Shpiro, E. S.; Tkachenko, O. P.; Jaeger, N. I.; Schulz-Ekloff, G.; Grünert, W. J. Phys. Chem. B 1998, 102, 3798-3805.

(44) Somorjai, G. A.; Hwang, K. S.; Parker, J. S. Top. Catal. 2003, 26 , 87-99.

(45) Bouwman, R.; Sachtler, W. H. M. J. Catal. 1970, 19, 127.

(46) Chakraborty, D.; Kulkarni, P. P.; Kovalchuk, V. I.; d'Itri, J. L. Catal. Today 2004, 88, 169-181.

(47) Bourane, A.; Bianchi, D. J. Catal. 2002, 209, 114-125. 


\title{
Supporting Information
}

\section{Tuning Supported Catalyst Reactivity with Dendrimer Templated Pt-Cu Nanoparticles}

\author{
Natalie N Hoover, Bethany J. Auten, and Bert D. Chandler* \\ Department of Chemistry, Trinity University, One Trinity Place, San Antonio, TX 78212-7200 \\ bert.chandler@trinity.edu
}

\section{Contents:}

S-2 Figure S-1: UV-Visible spectroscopic study of $\mathrm{PtCl}_{4}{ }^{-}$complexation by G5-OH.

Figure S-2: Low coverage infrared spectra of CO bound to the bimetallic catalysts.. 
Figure S-1. UV-Visible spectroscopic study of $\mathrm{PtCl}_{4}^{-}$ complexation by $\mathrm{G} 5-\mathrm{OH}$.

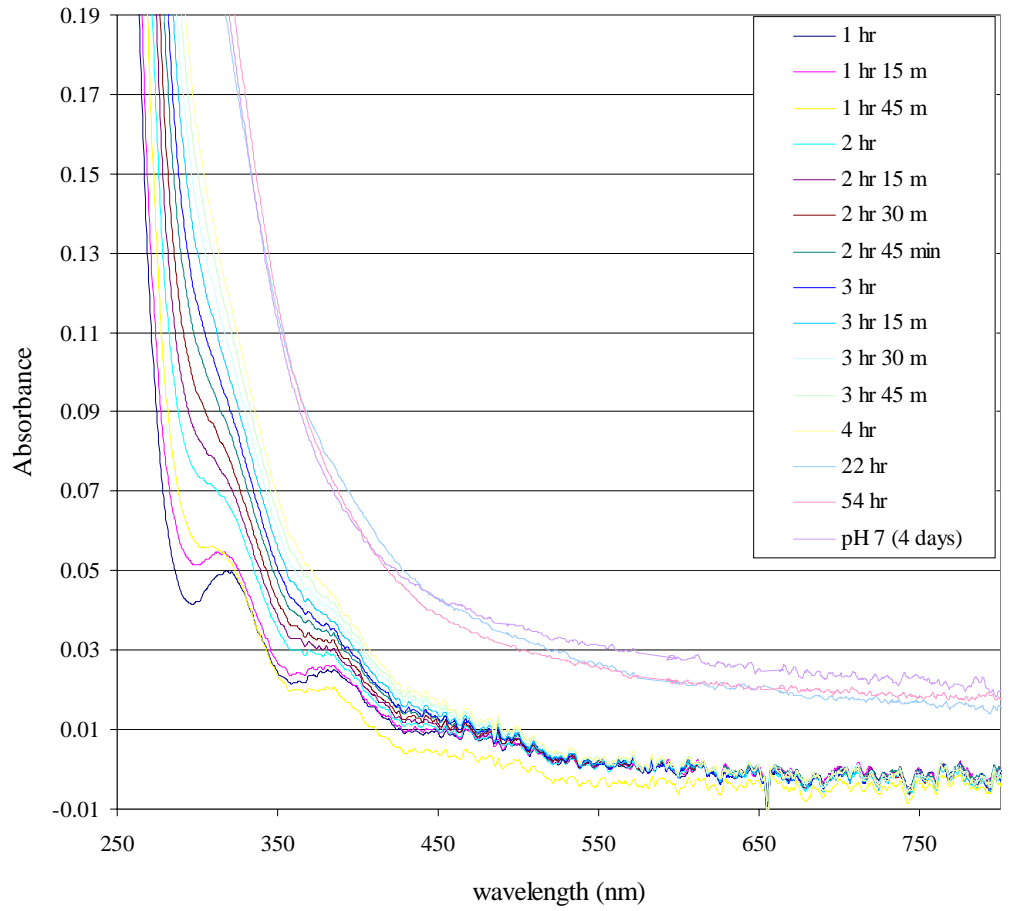

Figure S-2. Low coverage infrared spectra of CO bound to the bimetallic catalysts. The $\mathrm{Pt}_{15} \mathrm{Cu}_{30}$ spectrum was collected while most $\mathrm{CO}$ was still bound to the catalyst. The low loading and rapid $\mathrm{CO}$ desorption made collection of low coverage spectra comparable to the other catalysts untenable. 